\title{
Cine, valores humanos y cultura de paz: Conflicto y armonía. Derrotero de una experiencia educomunicativa
}

\author{
Fernando Ruiz Vallejos
}

1/ Cine y valores humanos" es un proyecto de la Facultad de Comunicación de la Universidad de Lima de introducción a la cultura cinematográfica, organizado por el profesor Fernando Ruiz Vallejos. Está dirigido a los alumnos de tercero, cuarto y quinto de secundaria, y a los profesores de colegios de Lima metropolitana. Se trata de brindar formación en apreciación cinematográfica y crear un espacio de intercambio y reflexión sobre los valores enunciados o sugeridos a través del cine.

Dicho proyecto se viene desarrollando ininterrumpidamente desde el año 2003, y desde el 2005 forma parte de la Cátedra Unesco "Comunicación y cultura de paz", otorgada por dicha institución a la Facultad de Comunicación de la Universidad de Lima

Para la etapa en la que se encuentran los estudiantes secundarios y el ambiente de búsqueda y posible desorientación, esta actividad supone un espacio de relación entre educando y educadores, sugerente por diversas razones: el cine y los valores, el audi- torio hecho aula y el encuentro con el recinto universitario. En ese entorno, la conversación acerca de los valores se plantea no en forma compulsiva sino a partir de una serena sensibilización, desencadenada por propuestas cinematográficas diversas. No se trata, pues, de imponer sino de descubrir juntos, alentando la participación.

En estos siete años, hemos ido aquilatando interesantes procesos. En principio, la prueba de entrada evidencia desconocimiento casi absoluto de los elementos del lenguaje cinematográfico y la apreciación cinematográfica. Luego, la prueba de salida muestra una notable mejoría y hasta sorprendentes resultados en la elaboración de trabajos de apreciación cinematográfica.

En ese sentido, los cine-foros llegan a constituir un encuentro con el arte, la historia, la antropología cultural, y con las ciencias sociales en conjunto. Pero no es solo eso, el ritmo de las obras cinematográficas, su forma de expresión a través del guión, el conjunto de elementos audiovisuales, 
la propuesta y desarrollo de los personajes y las situaciones, tratados en profundidad por realizadores de calidad, propician una especial forma de expresión y desde luego contribuyen a una sensibilización de los estudiantes. El mundo de realizadores como Ingmar Bergman, Akira Kurosawa, Roberto Rossellini, François Truffaut, Martin Scorsese, al lado de los directores latinoamericanos Walter Salles, Francisco Lombardi, Adolfo Aristaraín, Tomás Gutiérrez Alea y muchos otros, revela un espacio de opciones estéticas y culturales que ciertamente enriquecen y forman. Dicha sensibilización tiene personería estética pero también de autoafirmación, pues el joven opina, sale de sí mismo para compartir lo suyo y con ello desecha o confirma su apreciación, y por sobre todo, expresa. Esa expresión alimenta su afirmación, cada vez se autoconstruye en sensaciones y apreciaciones y ello, creemos, coadyuva al crecimiento de su personalidad.

A manera de ejemplo comentamos lo ocurrido en las sesiones de cinedebate con las películas Europa Europa de Agnieska Holland y El laberinto del fauno de Guillermo del Toro.

En el caso de Europa, Europa la discusión incidió en la discriminación ra- cial, la carencia de sentido democrático, la falta de libertad y el penoso recorrido del protagonista para sobrevivir durante la Segunda Guerra Mundial. En lo que respecta a El laberinto del fauno el debate fue aún más encendido; se hizo hincapié en la fantasía, pureza de espíritu, valentía y solidaridad en el marco de la guerra civil española. En ambos casos el eje de discusión ha sido la paz, en relación a la dignidad humana.

Ciertamente, en las diversas clases del curso o las sesiones de cine-debates se plantea la idea de cultura de paz como la entiende el ex director general de la Unesco Federico Mayor Zaragoza: "La paz debe construirse con el ejercicio de los derechos humanos, sabiendo que hay un derecho fundamental que es la vida".*

En esta relación entre el cine, los educandos y los educadores hemos encontrado conflicto y armonía. Conflicto entre el cine estereotipado como motivo de evasión y el cine de calidad. Conflicto entre las miradas prejuiciosas y las miradas profundas frente al cine. Conflicto de las obras cinematográficas mismas: conflicto creativo, que profundiza en la condición humana. Armonía, finalmente, en el principio de aprender comuni-

* Escritura pública. “El escaparate: Entrevista a Federico Mayor Zaragoza" [en línea]. $<$ htpp:// wwwnotariado.org/publicaciones/escritura/números/54/04.htm>. [Consulta: 3 de diciembre del 2008]. 
cando, viendo, apreciando, juzgando, motivando a una cultura de paz que anime a los jóvenes escolares y sus profesores a asumir el sentido de justicia social.

Si se hace un recuento de lo descrito se tiene un cúmulo de personajes y situaciones que implican una continua reflexión respecto a la condición humana: los valores puestos a prueba. El joven espectador y el profesor van usualmente al cine para entretenerse, sin embargo, como lo plantea el crítico y cineasta belga Franz Weyerganz, los grandes filmes implican mucho más: un sentimiento de plenitud. Esa atmósfera de plenitud se ve expresada en los rostros de los participantes cuando dialogan y descubren el sentido de los elementos del lenguaje cinematográfico y el sentido de las obras en su conjunto, las relaciones que se pueden establecer con sus propias experiencias.

Esta experiencia, cuyo protagonista es el cine, ha cumplido siete años ininterrumpidos; durante ese tiempo aproximadamente setecientos alumnos, doscientos profesores y más de cien colegios han experimentado el conflicto y la armonía en procesos de edu-comunicación. 
Fernando Ruiz 